Trivium: Estudos Interdisciplinares, Ano XIII, Ed. 2. p. 124-127.

http://dx.doi.org/10.18379/2176-4891.2021v2p.124

\title{
O trabalho do luto na série Fleabag, de Phoebe Waller-Bridge
}

\section{The grieving process on the series Fleabag, by Phoebe Waller-Bridge}

\author{
El trabajo del duelo en la serie Fleabag, de Phoebe Waller-Bridge
}

Le travail du deuil dans la série Fleabag, de Phoebe Waller-Bridge

Arthur Teixeira Pereira*

Two Brothers Pictures (Produtor), Bradbeer, H., \& Kirkby, T. (Diretores). (2016-19). Fleabag. Califórnia: Amazon Studios.

Fleabag é uma série de comédia dramática britânica escrita por Phoebe WallerBridge, dirigida por Harry Bradbeer e Tim Kirkby e produzida pela Two Brothers Pictures para o canal digital BBC Three, em um contrato de coprodução com a Amazon Studios. Foi lançada em 2016 e conta com duas temporadas de seis episódios cada, tendo a segunda temporada sido lançada em 2019. A série recebeu diversas indicações a prêmios, dentre os quais venceu o Prêmio Emmy do Primetime, nas categorias de "Séries de comédia" e "Atriz principal", além de ter ganhado o Globo de Ouro de Melhor Série de Televisão e de Melhor Atriz (por Waller-Bridge) em 2020.

A série aborda a história de uma britânica nomeada como Fleabag - embora nenhum personagem a chame pelo nome ao longo dos doze episódios que compõem a obra - interpretada por Phoebe Waller-Bridge. No decorrer dos episódios, vemos que a protagonista é proprietária de um café, enfrenta problemas financeiros e costuma envolver-se sexualmente com diferentes homens, mas nunca parece estar completamente satisfeita com qualquer um deles. Logo nos primeiros minutos da série, conhecemos Claire (Sian Clifford), irmã da protagonista, que é completamente diferente: tem um cargo importante em uma grande empresa, é casada e tem um enteado adolescente. Ao contrário de Fleabag, Claire é uma mulher organizada e com muito pudor.

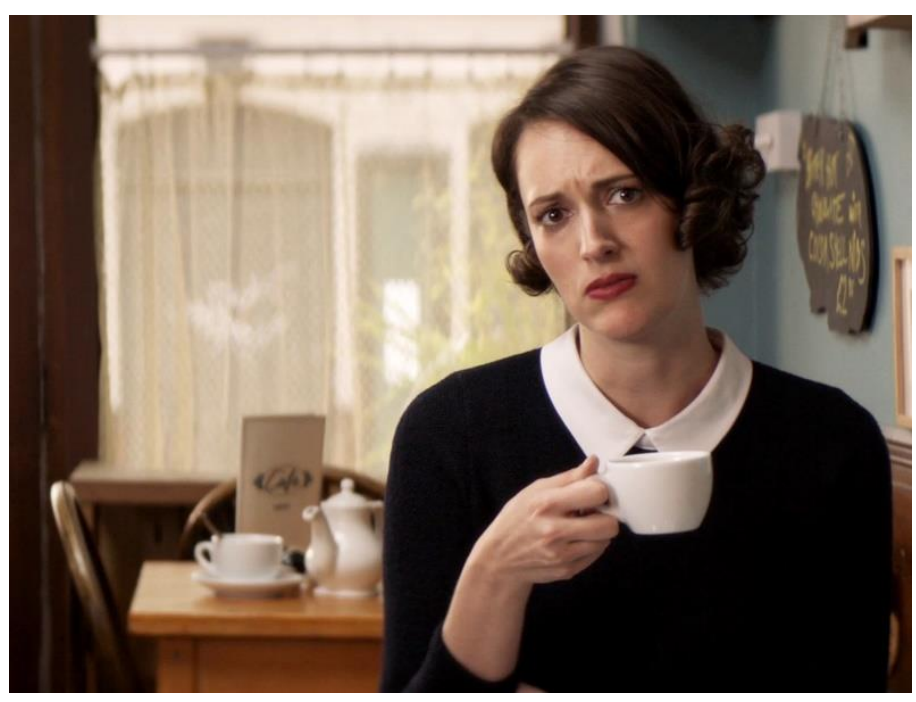

Além de sua irmã, a série também apresenta outros personagens, como seu pai (Bill Paterson) e sua madrinha e madrasta (Olivia Colman), que curiosamente não têm nome. Inclusive, a ausência de nome de alguns personagens é um recurso comum na série; a própria protagonista não é nomeada por nenhum personagem, apenas temos acesso ao nome "Fleabag", que pode ser traduzido como "saco de pulgas" ou "espelunca", isto é, algo incômodo ou mal cuidado. Além disso, a obra também conta com um recurso bastante inovador - denominado popularmente como "quebra da quarta parede" - através 
do qual a personagem principal dialoga com o telespectador. Assim, em diversos momentos, Fleabag se dirige às câmeras, comentando com o público as situações que lhe ocorrem, de modo tal que os personagens ao seu redor não participam desse diálogo.

Em diferentes pontos da narrativa, entrecortam-se cenas do passado, revelando que Fleabag tinha uma amiga muito próxima chamada Boo (Jenny Rainsford), que se suicidou atirando-se entre os carros de uma avenida após descobrir que havia sido traída pelo namorado. A primeira temporada mantém em segredo de que forma isso teria ocorrido, mas, ao final do sexto episódio, descobrimos que a própria Fleabag fora a amante do namorado de Boo, embora esta não soubesse disso. No mesmo episódio, a protagonista relata, aos prantos, que se sente completamente sozinha, pois sente que "estraga tudo ao seu redor", incluindo a família e a vida de Boo. Vemos, nesta passagem, o sentimento de culpa que Fleabag carrega por suas escolhas.

Com frequência, a personagem-título encontra-se em situações embaraçosas ou de teor dramático, como seu relacionamento amoroso com Harry (Hugh Skinner), que com frequência atravessa problemas de convivência e acaba chegando ao fím, além de sua baixa autoestima e suas dificuldades financeiras. Ademais, sua irmã, Claire, também enfrenta muitos problemas no casamento e no trabalho. Embora seja uma série de comédia, Fleabag apresenta temas sérios, desvelando um drama como fundo da narrativa da protagonista.

Na segunda temporada, acompanhamos um pouco mais da história da personagem principal. É introduzido na série um novo personagem, o padre (Andrew Scott), por quem Fleabag se apaixona e que, assim como diversos outros personagens, não tem um nome. São apresentadas também maiores informações sobre as relações familiares da protagonista, especificamente sua reação à morte da mãe. Não temos acesso ao nome e nem sequer à imagem da mãe, mas, em momentos cruciais da série, vemos referências a ela, seja através de falas dos personagens, seja por meio de cenas de seu velório.

Aos poucos, vemos que o luto pela morte da mãe, aliado ao luto e culpa pelo suicídio da amiga Boo, é o contorno da narrativa da série. A protagonista parece estar às voltas com o processo de enlutamento, tentando reencontrar seu lugar na vida. Em uma confissão que faz ao padre, a personagem afirma, em tom emocionado, que necessita de alguém que lhe diga exatamente o que vestir, o que comer e como viver, pois sente que não sabe mais como fazer isso. Embora a série seja repleta de cenas de humor, constatamos uma tristeza como pano de fundo do desenvolvimento da protagonista.

No ensaio Luto e melancolia, Freud (1917/2010, p. 172) descreve o luto como uma "reação à perda de uma pessoa amada ou de uma abstração que ocupa seu lugar, como pátria, liberdade, um ideal etc.". O processo de enlutamento seria caracterizado por uma perda de interesse no mundo ao redor, carregada de um doloroso abatimento. Não por acaso, Freud (1917/2010, p. 176) ressalta que no trabalho do luto "o mundo se torna pobre e vazio". Semelhante a este sentimento descrito por Freud, no quarto episódio da primeira temporada, Fleabag confessa que sente vontade de chorar o tempo todo, sem dar maiores explicações do motivo disso. A série é contornada por vários momentos como esse, em que a comédia é entrecortada por um drama ou por uma situação embaraçosa.

Freud aponta para um trabalho em jogo no processo de enlutamento, o denominado trabalho do luto (Trauerarbeit). Ressalta-se que, em alemão, Trauer pode significar tanto "luto" como "tristeza". Assim, independentemente do significado atribuído, há um sofrimento implicado nesse processo. $\mathrm{O}$ autor descreve que as vivências de perda muitas vezes se configuram como experiências de difícil elaboração, de modo que o luto seria um trabalho de elaboração dessas perdas, que se podem apresentar de diferentes formas para cada sujeito. 
Freud (1917/2010, p. 173) destaca o que denomina de "exame da realidade", segundo o qual o sujeito constata que o objeto amado não mais existe, o que lhe exige que toda a libido investida no objeto perdido tenha que ser retirada. Trata-se de um trabalho no qual o sujeito se implica em desinvestir o objeto perdido. Esse não é, no entanto, um trabalho simples, muito menos ligeiro, na medida em que a "existência do objeto perdido se prolonga na psique" (Freud, 1917/2010, p. 174). Por meio do trabalho do luto, é possível ao sujeito simbolizar e elaborar a perda, engendrando um desligamento da libido relativa às lembranças - e também às expectativas (Cavalcanti, Samczuk \& Bonfim, 2013) - relacionadas ao objeto perdido, de modo que se encontram novos substitutos para ele.

Nesse sentido, os rituais funerários cumprem uma função importante, já que contribuem para a simbolização da perda, isto é, promovem um contorno para a morte do ente querido. Na cena do velório da mãe de Fleabag, ocorrida no quarto episódio da segunda temporada, vemos uma parte da elaboração do luto acontecer no momento em que a personagem desabafa com sua amiga Boo, dizendo em tom choroso: "Não sei o que fazer com [...] todo o amor que sinto por ela [pela mãe falecida]. Não sei onde colocar agora". Boo, por sua vez, indica-lhe que todo esse sentimento "precisa ir para algum lugar". Esta cena nos remete ao que Freud afirma acerca do trabalho de desinvestimento no objeto perdido. É digno de nota que a protagonista passe a se envolver com frequência em relações amorosas pouco duradouras. No segundo episódio da segunda temporada, Fleabag chega a afirmar que usa o sexo como forma de preencher o vazio que sente dentro de si. Estaria ela tentando redirecionar seu investimento libidinal no mundo?

Lo Bianco e Costa-Moura (2020, p. 7) levantam a pergunta "que lugar a pessoa que morreu ocupava na vida de cada pessoa com quem ela convivia?" para indicar um aspecto de coletividade implicado no trabalho do luto. Trata-se do lugar que o morto ocupa para o enlutado, mas não se resume a isso, pois inclui também o lugar que era dado ao enlutado na vida social pela sua relação com aquele que morreu. Assim, as autoras concluem que é "sob a perspectiva de um trabalho que reinstaura o lugar perdido do sujeito que podemos entender o luto como parte de uma reverência feita à morte" (Lo Bianco \& Costa-Moura, 2020, p. 7).

Ao final do primeiro episódio da primeira temporada, a protagonista visita a casa do pai e depara-se com uma pequena escultura valiosa de um corpo feminino nu na estante de sua madrinha. Fleabag interessa-se pela peça e, como sua madrinha nega dar-lhe a escultura de presente, a protagonista a rouba. Esta peça circula ao longo da série, passando pelas mãos de diferentes personagens em diferentes contextos, mas, ao final, retorna para Fleabag. É curioso que, justamente no episódio de encerramento da série, quando seu pai e sua madrinha estão prestes a casar-se, esta revele à protagonista que a escultura foi baseada na imagem de sua mãe. Parece-nos que, de alguma forma e mesmo sem saber, Fleabag persistia em carregar e fazer circular consigo uma parte de sua mãe ao longo da série.

Conforme apontado anteriormente, ao longo da segunda temporada, a personagem se apaixona por um padre. Eles chegam a relacionar-se sexualmente por um período de tempo, mas, nos últimos minutos da série, o padre revela ter escolhido a igreja, de modo que a relação dos dois chega ao fim. Assim, a cena final nos mostra Fleabag sozinha, despedindo-se do público, acompanhada de uma parte de sua mãe, isto é, da escultura que havia roubado no primeiro episódio. Sua face é enquadrada pela câmera e a protagonista faz um gesto com a cabeça expressando um "não" para o telespectador, caminhando para longe em seguida. Essa parece ser uma despedida final, uma representação de que teria sido possível elaborar algo pela personagem ali, naquele intervalo das duas temporadas. 
Fleabag é, portanto, uma obra que nos leva a refletir sobre o trabalho do luto, entre outros temas importantes. De forma leve e bem humorada, a série não deixa de tratar com seriedade o processo do luto da protagonista, demonstrando o que Freud já havia apontado acerca do trabalho de desinvestimento no objeto perdido que está em jogo no luto. Ressalta-se que, com esta resenha, não se pretendeu estabelecer uma análise psicológica de Fleabag, visto que ela é apenas uma personagem fictícia, mas, sim, extrair da obra elementos que podem ser importantes para se refletir sobre a morte e o luto a partir da perspectiva da psicanálise.

\section{Referências}

Cavalcanti, A. K. S., Samczuk, M. L., \& Bonfim, T. E. (2013). O conceito psicanalítico do luto: uma perspectiva a partir de Freud e Klein. Psicólogo inFormação, 17(17), 87-105. Recuperado http://pepsic.bvsalud.org/pdf/psicoinfo/v17n17/v17n17a07.pdf

Freud, S. (2010). Luto e melancolia. In Obras Completas, v. 12. São Paulo: Companhia das letras. (Obra original publicada em 1917).

Lo Bianco, A. C., \& Costa-Moura, F. (2020). Covid-19: Luto, Morte e a Sustentação do Laço Social. Psicologia: Ciência e Profissão, 40, 1-11. https://doi.org/10.1590/1982-3703003244103

Citação/Citation: Pereira. A. T. (2021). O trabalho do luto na série Fleabag, de Phoebe Waller-Bridge. Trivium: Estudos Interdisciplinares (Ano XIII, Ed.2), pp. 3-13.

Recebido em: 23/07/2021

Aprovado em: 28/08/2021 